九州大学学術情報リポジトリ

Kyushu University Institutional Repository

\title{
Mathematical Relationships between Basic Growth Function and Bondi K-Factor
}

Shimojo, Masataka

九州大学大学院農学研究院資源生物科学部門動物 · 海洋生物資源学講座

Nakano, Yutaka

University Farm, Faculty of Agriculture, Kyushu University

https://doi.org/10.5109/22064

出版情報：九州大学大学院農学研究院紀要. 57 (1)，pp. 153-154，2012-02. Faculty of Agriculture， Kyushu University

バージョン :

権利関係 : 


\title{
Mathematical Relationships between Basic Growth Function and Bondi K-Factor
}

\author{
Masataka SHIMOJO* and Yutaka NAKANO ${ }^{1}$ \\ Laboratory of Regulation in Metabolism and Behavior, Division of Animal and Marine Bioresource Sciences, \\ Department of Bioresource Sciences, Faculty of Agriculture, \\ Kyushu University, Fukuoka 812-8581, Japan
}

(Received October 31, 2011 and accepted November 9, 2011)

\begin{abstract}
This study was designed to investigate mathematical relationships between basic growth function and Bondi $\mathrm{K}$-factor from the viewpoint of 4-dimensional phenomena. The results obtained were as follows. Basic growth function was mathematically related to Bondi K-factor. The product of relative growth rate and time $(r \cdot t)$ where $W \cdot c^{2}$ replaced $W$ showed a closer mathematical relationship to natural logarithm of Bondi $\mathrm{K}$-factor. If based on these mathematical relationships, then basic growth phenomena look like 4-dimensional phenomena. Applying basic growth function to 3-dimensional body frame size was also discussed. In addition, appendix was added to give corrected versions to problems that were found in previous reports.
\end{abstract}

Key words: basic growth function, Bondi K-factor, exponential function, 4-dimension

\section{INTRODUCTION}

Basic growth analysis of a plant (Blackman, 1919) or an animal (Brody, 1945) is conducted using exponential function to analyze the weight increase with the passage of time. It is well known that exponential function is equal to Bondi $\mathrm{K}$-factor. Bondi $\mathrm{K}$-factor is one of the useful tools to investigate and explain 4-dimensional phenomena in physics (Bondi, 1964). Shimojo (2011a, 2011c) also investigated relationships between them, but in a report (Shimojo, 2011c) there are problems found that require further investigation.

The present study was designed to investigate mathematical relationships between basic growth function and Bondi $\mathrm{K}$-factor from the viewpoint of 4-dimensional phenomena.

\section{BASIC GROWTH FUNCTION AND BONDI K-FACTOR}

\section{Relative growth rate and basic growth function}

The following are differential equation for relative growth rate (1) and its solution (2),

$$
\begin{aligned}
& \frac{1}{W} \cdot \frac{d W}{d t}=r, \\
& W=W_{0} \exp (r \cdot t),
\end{aligned}
$$

where $W=$ weight, $t=$ time, $W_{0}=$ weight at $t=0, r=$ relative growth rate.

In the present study, $W$ is regarded as the weight of matter instead of a plant or an animal.

\footnotetext{
${ }^{1}$ University Farm, Faculty of Agriculture, Kyushu University, Kasuya, Fukuoka 811-2307
}

* Corresponding Author (E-mail: mshimojo@agr.kyushu-u.ac.jp)

\section{Bondi K-factor and exponential function}

Hyperbolic functions relate Lorentz transformation with exponential function, leading to expressions (3) and (4),

$$
\begin{gathered}
\exp (\theta)=\sqrt{\frac{1+v / c}{1-v / c}}, \\
\theta=\ln \left(\sqrt{\frac{1+v / c}{1-v / c}}\right),
\end{gathered}
$$

where $v=$ velocity of an object, $c=$ speed of light, $0 \leq v$ $<c, 0 \leq \theta<\infty, 1 \leq \exp (\theta)<\infty$, ln = natural logarithm. Bondi $\mathrm{K}$-factor is exponential function. Instead of Bondi $\mathrm{K}$-factor, exponential function may be used because the value of $v$ is determined from $\theta$. Boldly presuming from the mathematical viewpoint, exponential increases look like 4-dimensional phenomena.

\section{Basic growth function and Bondi K-factor}

A mathematical application of expression (3) to basic growth function (2) leads to

$$
\exp (r \cdot t)=\sqrt{\frac{1+v / c}{1-v / c}} .
$$

Since $r$ is actually the mean value over the interval $t_{\mathbf{1}}$ to $t_{2}$, expression (6) is given,

$$
\begin{aligned}
& \frac{\ln W_{2}-\ln W_{1}}{t_{2}-t_{1}} \cdot\left(t_{2}-t_{1}\right) \\
= & \frac{\ln \left(W_{2} \cdot c^{2}\right)-\ln \left(W_{1} \cdot c^{2}\right)}{t_{2}-t_{1}} \cdot\left(t_{2}-t_{1}\right) \\
= & \ln \left(\sqrt{\frac{1+v / c}{1-v / c}}\right) .
\end{aligned}
$$

Expression (5) shows that basic growth function is 
mathematically related to Bondi $\mathrm{K}$-factor. Expression (6) shows that the product of relative growth rate and time $(r \cdot t)$ where $W \cdot c^{2}$ replaces $W$ has a closer mathematical relationship to natural logarithm of Bondi $\mathrm{K}$-factor, a mathematical relationship between $r \cdot t$ and $v / c$. If based on these mathematical relationships, then basic growth phenomena look like 4-dimensional phenomena. Basic growth function may also be applied to the analysis of 3-dimensional body frame size $(X, Y, Z)$ of matter, for example, a report by Shimojo et al. (2009) for a plant or an animal. Whether or not the growth of matter $(W, X$, $Y, Z$ ) looks like 4-dimensional phenomenon requires further investigation. In addition, expressions (5) and (6) are corrected versions to problems that were found in a previous report (Shimojo, 2011c) where only $r$ was related to the natural logarithm of Bondi $\mathrm{K}$-factor.

\section{Properties of Bondi K-factor including Lorentz fac- tor} follows

Bondi $\mathrm{K}$-factor $(B)$ includes Lorentz factor $(L)$ as

$$
\sqrt{\frac{1+v / c}{1-v / c}}=\frac{1}{\sqrt{1-(v / c)^{2}}}\left(1+\frac{v}{c}\right) .
$$

If Bondi $\mathrm{K}$-factor and Lorentz factor are hypothetically regarded as functions of $v$, then

$$
\begin{gathered}
\frac{(d B(v) / d t)^{2}}{B(v)\left(d^{2} B(v) / d t^{2}\right)}=\frac{c}{c+2 v}, \\
\frac{(d L(v) / d t)^{2}}{L(v)\left(d^{2} L(v) / d t^{2}\right)}=\frac{v^{2}}{c^{2}+2 v^{2}} .
\end{gathered}
$$

Since $0 \leq v<c$, the following inequality is given,

$$
0 \leq \frac{v^{2}}{c^{2}+2 v^{2}}<\frac{1}{3}<\frac{c}{c+2 v} \leq 1
$$

This is compared with the case of exponential function $(e(\theta))$ that is given by expression (11),

$$
\frac{(d e(\theta) / d t)^{2}}{e(\theta)\left(d^{2} e(\theta) / d t^{2}\right)}=1
$$

What the inequality (10) shows remains to be investigated.

\section{Appendix: the form of expression (11) and com- plex wave function}

Shimojo (2011b) showed that expression (11) was given by complex wave function (12) as well as basic growth function (2),

$$
\phi=A \cdot \exp \left(\left(\boldsymbol{i} \cdot F^{\prime}\right) \cdot t\right), \quad(12) \quad W=W_{\mathbf{0}} \exp (r \cdot t)
$$

where $\phi=$ wave function, $\boldsymbol{i}=$ imaginary unit, $A=$ amplitude, $F=$ term related to frequency. Shimojo (2011b) compared functions (12) and (2) to investigate hypothetic wave-matter relationships, but there was a problem in the hypothetic interpretation of $F$ as $f / A$, the number of frequencies $(f)$ divided by amplitude $(A)$. The corrected version is $F$ = frequency, and hypothetic wavematter relationships are: (high $A$, high $F$ ) - (high $W_{0}$, high $r$ ), (high $A$, low $F$ ) - (high $W_{0}$, low $r$ ), (low $A$, high $F^{\prime}$ ) - (low $W_{\mathbf{0}}$, high $r$ ), (low $A$, low $F$ )-(low $W_{\mathbf{0}}$, low $r$ ).

In addition, complex wave function (12) is extended as follows,

$$
\begin{aligned}
& \phi(x, t)=A \cdot \exp ((\boldsymbol{i} /(h / 2 \pi)) \cdot(p \cdot x-E \cdot t)), \\
& \phi^{*}(x, t)=A \cdot \exp ((-\boldsymbol{i} /(h / 2 \pi)) \cdot(p \cdot x-E \cdot t)), \\
& \phi^{*}(x, t) \cdot \phi(x \cdot t)=|\phi(x, t)|^{2}
\end{aligned}
$$

where $h=$ Planck's constant, $\pi$ : = circular constant, $p=$ momentum, $x$ position, $E=$ energy. The expression $(13-3)$ is a corrected version to $|\phi(x, t)|^{2}=1$ in a previous report (Shimojo, 2011c).

\section{Conclusions}

It is suggested that basic growth phenomena look like 4-dimensional phenomena when the product of relative growth rate and time is mathematically related to natural logarithm of Bondi $\mathrm{K}$-factor.

\section{ACKNOWLEDGEMENTS}

This study was supported by a Grant-in-Aid for Challenging Exploratory Research from Japan Society for the Promotion of Science (No. 21658089).

\section{REFERENCES}

Blackman, V. H. 1919 The compound interest law and plant growth. Ann. Bot., 33: 353-360

Bondi, H. 1964 Relativity and Common Sense (Doubleday and Company Inc., New York and Canada). Translation into Japanese by T. Yamanouchi for publication (1967), Kawade Shobo Publishers, Tokyo.

Brody, S. 1945 Time relations of growth of individuals and populations. In "Bioenergetics and growth - with special reference to the efficiency complex in domestic animals", Reinhold Publishing Corporation, New York, pp. 484-574

Shimojo, M., Y. Asano, R. Ishiwaka, Y. Nakano, M. Tobisa, N. Ohba, M. Eguchi and Y. Masuda 2009 Introducing viewpoints of mechanics into basic growth analysis - (IX) Hypothetic quasifour-dimensional growth mechanics -. J. Fac. Agr., Kyushu Univ., 54: 137-139

Shimojo, M. 2011a Symmetry in motion in Euler's formula and its breakdown in hyperbolic function and growth function. $J$. Fac. Agr., Kyushu Univ., 56: 79-81

Shimojo, M. 2011b Amplitude-frequency relationships in simplified wave function compared with weight-relative growth rate relationships in basic growth function. J. Fac. Agr., Kyushu Univ., 56: 83-84

Shimojo, M. 2011c Exponential function, Bondi K-factor and imaginary unit. J. Fac. Agr., Kyushu Univ., 56: 285-286 